\title{
Evolution of Psychosomatic Diagnosis in DSM. Historical Perspectives and New Development for Internists
}

\author{
RAMONA MOLDOVAN ${ }^{1}$, MĂDĂLINA RADU, ADRIANA BĂBAN ${ }^{1}$, D.L. DUMITRAŞCU ${ }^{2}$ \\ 1 "Babeş-Bolyai" University, Cluj, Department of Psychology \\ 2"Iuliu-Hațieganu” University of Medicine and Farmacy, Medical Clinic II
}

\begin{abstract}
The so-called "Psychosomatic symptoms" represent a real challenge for internists. These have often been described as non-specific, non-organic, functional, dysfunctional or idiopathic. These "diagnostic puzzles" are obviously difficult to treat. Psychosomatic symptoms have been categorized as hysteria, psychogenic, psychosomatic, conversion, somatization and somatoform disorder. It is only when modern classificatory systems such as the Diagnostic and Statistical Manual of Mental Disorders (DSM) and the International Classification of Diseases (ICD) were developed that research was stimulated and new clinical developments became much stronger than any other time. The current paper is aimed at briefly presenting the evolution of psychosomatic symptoms in DSM while pointing out the major milestones as well as the benefits and challenges along the way. We discuss the perspectives open with the advent of the $5^{\text {th }}$ edition the DSM-V.
\end{abstract}

Key words: Diagnostic and Statistical Manual of Mental Disorders, psychosomatic symptoms.

Physical symptoms in the absence of an identifiable organic correlation are rather common in health care $[1,2]$. Complaints such as chronic pain, headache, dyspnea, joint pain, chest pain, dizziness, palpitations and fatigue fall into this category. Symptoms like these have often been difficult to describe with a satisfactory term. Although recognition of the interaction between psyche and soma dates from antiquity, only recently did we refine the vocabulary and concepts to elucidate and systematically investigate its manifestations [3]. Psychosomatic disorders have always been described in various forms and often with interchangeable terms, all of which seeking recognition of the interaction between the mind and the body of an individual.

\section{HISTORICAL PERSPECTIVES}

For centuries, physicians have recognized psychosomatic symptoms. They have given a variety of overlapping labels that were sometimes inter-changeable.

This was particularly true to the terms "hysteria" and "hypochondriasis" [4, 5]. In 1682 Sydenham has made one of the first systematic descriptions of the physical and psychological symptoms that are seen in psychosomatic disorders. He thought hysteria to be condition that "can simulate any medical illness" and he believed it is diagnosed mainly in women, whereas hypochondriasis was seen mainly in men [6]. They were both considered a disturbance of the mind and an inconsistency of the body due to disorders of "animal spirits". In 1799 Sims explicitly distinguished hysteria from hypochondriasis by pointing out that hysteria is associated with a fluctuating mood, whereas hypochondriasis is best characterized by melancholy [6]. In the $19^{\text {th }}$ century, Briquet made a detailed description of 430 cases of hysteria and later on, Reynold and Charcoal also agreed that hysteria is a disease of the central nervous system [7]. Several years later, Freud and Breuer offered new perspectives on hysteria (their description will be later known as conversion disorder), which was seen as a transformation of emotional distress in physical symptoms (Breuer \& Freud, 1893). Freud attributed the emergence of somatic symptoms to unconscious mental processes (Breuer \& Freud, 1893: Studies on hysteria. On the psychical mechanism of hysterical phenomena: Preliminary communication. The standard edition of the complete psychological works of Sigmund Freud, vol. 2, pp. 1-18, London: Hogarth Press).

Hysterical symptoms were believed to be the result of the mental mechanism of dissociation and subsequent conversion and were conceptualized as a displacement of mental energy towards the body to avoid unbearable mental stress. A couple of decades later, the term somatisation was introduced by one of his followers - Stekel (for details see 8 ). 
Following a similar theoretical approach, Menninger (1947: Psychosomatic medicine: somatisation reactions. Psychol Med, 9, 92-97.) extended the concept of somatisation by defining "somatisation reactions" as the "visceral expressions of the anxiety which is thereby prevented from being conscious" [9]. Another major milestone in the evolution of these concepts was Menninger's change in 1947 of somatization into a state of mind of what has been previously been approached mostly as a neurotic trait [8].

Lipowski's subsequent developments [10] had an important contribution in setting up consultation-liaison psychiatry [11] and later on psychosomatic medicine. The current interdisciplinary framework in approaching somatic symptoms and psychosocial factors affecting the individual vulnerability as well as the course and correlates of psychosomatic disorders has undoubtedly gone through a sinuous process [12]. Clearly, there are a number of terms that have been used in describing psychosomatic disorders: psychogenic, psychosomatic, conversion, somatization, hypochondriasis. The symptoms have taken many names over the years. As a matter of fact, before the mid- $20^{\text {th }}$ century, psychiatric diagnoses were rather inconsistent and varied greatly from hospital to hospital and even from one professional to another (although a fair agreement on the major categories has always been recognized) [3]. It is only when modern classificatory systems such as the Diagnostic and Statistical Manual of Mental Disorders and the International Classification of Diseases were developed; that research was stimulated and new clinical developments became much stronger than any other time.

\section{THE DEVELOPMENT OF PSYCHOSOMATIC DIAGNOSIS IN DSM}

The first Diagnostic and Statistical Manual of Mental Disorders (DSM I) was developed between 1947 and 1951, just after the Second World War. DSM I is deeply influenced by the context of that time, where a high frequency of the psychological problems listed was introduced after having been observed in individuals who had previously been enrolled in the army. In this sense, most of the nonpsychotic mental disorders were seen as a response to military service and combat involvement. Another aspect that needs to be taken into account is that a great number of DSM I contributors were influenced by psychoanalysis and this was amply reflected in this edition. Hence, except for organic brain disorders and mental deficiencies (i.e. retardation), most mental disorders were seen as "reactions" [13].
DSM I included a section called Psychophysiological autonomic and visceral disorders. This term was used in preference to psychosomatic disorders, since this term was believed to refer to one of medicine's viewpoints on the discipline as a whole rather than to specific conditions. These reactions were believed to represent the visceral expression of affect which may be thereby largely prevented from being conscious. Symptoms were thought to be caused by a chronic and exaggerated state of the normal physiological expression of emotions, where subjective feelings may have been repressed. It was also believed that living such visceral states over a long period of time can lead to structural changes [13].

Psychophysiological disorders were subcategorized into ten "reactions" of various organ systems and had a variety of symptoms such as headaches, back pain, asthma, constipation etc. [13]: Psychophysiological skin reaction; Psychophysiological musculoskeletal reaction; Psychophysiological respiratory reaction; Psychophysiological cardiovascular reaction; Psychophysiological hemic and lymphatic reaction; Psychophysiological gastrointestinal reaction; Psychophysiological genitourinary reaction; Psychophysiological endocrine reaction; Psychophysiological nervous system reaction; Psychophysiological reaction of organs of special sense.

The conceptualization advanced by DSM I was primarily psychodynamic/ psychoanalytic particularly since Franz Alexander, Co-Director of the Chicago Psychoanalytic Institute and one of the very prominent figures in the psychosomatic field at that time was a member of the committee that developed DSM I [3].

In 1968, 16 years later, a second edition of the manual was published in a time period where more emphasis was put on empirical research such as the idiographic approach and clinical observations. Although the general features and categories were very similar to the original edition, DSM II included several changes: in this second version of the manual the terms such as "reaction" were excluded and a new terminology was adopted: neurosis, psychosis, disorder. Psychosomatic conditions became Psychophysiological disorders, with "autonomic and visceral" dropped, yet the diagnosis criteria for these disorders remained largely the same [13]. Although DSM II had a biomedical approach, rather than a bio-psychosocial one, a number of developments were included and even more advances were to be included in the next edition of DSM: American psychiatry was becoming more and more scientific, increasingly emphasizing evidence-based diagnosis 
and treatment and stressing the need of controlled research.

DSM III was released in 1980, twelve years later. A number of changes were made in this edition, the most significant ones being: 1) the naming of conditions described as disorders; 2) the listing of specific criteria to be used as the basis for diagnosis; 3) the organization of diagnostic categories in a hierarchical manner [3]. A new feature of DSM III was the multiaxial format in which personality disorders, concomitant medical conditions, stressors and global functioning were included. As a matter of fact, the multiaxial system for evaluation is widely regarded as one of the most important contributions of DSM-III: Axis I: Clinical Disorders of Mental Illness; Axis II: Personality Disorders and Mental Retardation; Axis III: General Medical Conditions; Axis IV: Psychosocial and Environmental Problems and Axis V: Global Assessment of Functioning.

Experience DSM III revealed a number of instances in which the criteria were not entirely clear. Therefore, the American Psychiatric Association appointed a work group, under the direction of Spitzer, to revise DSM-III. Categories were renamed and reorganized, and significant changes in criteria were made as efforts were made for the diagnoses to be purely descriptive. The revisions and corrections led to the publication of DSM III R in 1987.

Psychophysiological disorders are no longer included in this edition; instead, a new category was added: Psychological factors affecting physical conditions. This category was mainly defined by psychological processes influencing physical (i.e. biological) conditions and was hoped to enable clinicians to note that psychological factors may contribute to the initiation or exacerbation of some physical condition. The physical condition referred to both somatic disorders and single symptoms (e.g. such as vomiting). The physical conditions were to be recorded on Axis III. This edition of DSM accepts the inclusion of several "psychological" factors, although it is by no means easy to delineate what this means. A limited yet useful explanation was the meaning ascribed by individuals to various environmental stimuli. Examples of such stimuli include the sights and sounds arising in interpersonal transactions, such as arguments, or finding out that a loved one has died. The individual may not be aware of the meaning that he or she has given to such stimuli or of the relationship between these stimuli and the initiation or exacerbation of the physical condition, yet they may have an impact on the individual's symptoms.
Having included psychological, biological, and social factors was aimed at reflecting a more complex and dynamic framework to be used when envisaging psychiatric disorders.

According to DSM III, the conclusion that psychological factors are affecting the physical condition requires evidence of a temporal relationship between the environmental stimuli as well as the meaning ascribed to them and the initiation or exacerbation of the physical condition. An evaluation was believed to be more certain when a temporal relationship is reported. This category was designed for any physical condition where psychological factors are judged to be contributory and was used to describe disorders that have been referred to as either "psychosomatic" or "psychophysiological". Common examples of physical conditions where this category may be appropriate include, but are not limited to: obesity, tension headache, migraine headache, angina pectoris, painful menstruation, sacroiliac pain, neurodermatitis, acne, rheumatoid arthritis, asthma, tachycardia, arrhythmia, gastric ulcer, duodenal ulcer, cardiospasm, pylorospasm, nausea and vomiting, regional enteritis, ulcerative colitis, and frequency of micturition [3]. This category was distinct from Conversion Disorders (which were regarded as disturbances in which the specific pathophysiological process involved in the disorder is not demonstrable by existing standard laboratory procedures and which are conceptualized with psychological constructs only).

Diagnostic criteria for Psychological Factors Affecting Physical Condition in DSM III were as follows:

A. Psychologically meaningful, environmental stimuli are temporally related to the initiation or exacerbation of a physical condition (recorded on Axis III).

B. The physical condition has either demonstrable organic pathology (e.g., rheumatoid arthritis) or a known pathophysiological process (e.g., migraine headache, vomiting).

C. The condition is not due to a Somatoform Disorder.

This edition of DSM also included a description of Somatization disorders, which consisted of a group of disorders characterized by physical symptoms, without being explained by organic factors. Hysteria, hypochondriasis and a new disorder, somatization, were included here. DSM-III derived the concept of somatization disorder from the criteria for Briquet's syndrome, as described and operationalized by Perley and Guze (1962: Hysteria. The stability and usefulness of clinical 
criteria. A quantitative study based on a follow-up period of six to eight years in 39 patients. $N$ Engl $J$ Med, 266, 421-6). Divided among 10 groups a total of 59 physical as well as psychological symptoms were enlisted among which 25 symptoms from nine groups were required to qualify for the diagnosis of somatization disorder. Later in an attempt to avoid overlapping with other diagnoses, all psychological symptoms were eliminated in the DSM-III modification [14].

Diagnostic criteria for Somatization Disorder as per DSM III are listed below:

A. A history of physical symptoms of several years' duration beginning before the age of 30 .

B. Complaints of at least 14 symptoms for women and 12 for men, from the 37 symptoms listed below.

Sickly: Believes that he or she has been sickly for a good part of his or her life.

Conversion or pseudo-neurological symptoms: Difficulty swallowing, loss of voice, deafness, double vision, blurred vision, blindness, fainting or loss of consciousness, memory loss, seizures or convulsions, trouble walking, paralysis or muscle weakness, urinary retention or difficulty urinating.

Gastrointestinal symptoms: Abdominal pain, nausea, vomiting spells (other than during pregnancy), bloating (gassy), intolerance (e.g., gets sick) of a variety of foods, diarrhea.

Female reproductive symptoms: judged by the individual as occurring more frequently or severely than in most women: painful menstruation, menstrual irregularity, excessive bleeding, severe vomiting throughout pregnancy or causing hospitalization during pregnancy.

Psychosexual symptoms: For the major part of the Individual's life after opportunities for sexual activity: sexual indifference, lack of pleasure during intercourse, pain during intercourse.

Pain: Pain in back/ joints, extremities, genital area (other than during intercourse); pain on urination; other pain (other than headaches).

Cardiopulmonary symptoms: Shortness of breath, palpitations, chest pain, dizziness.

Even decades after this decision, literature argues that the introduction of the somatization disorder in DSM III in 1980 has stimulated research and new clinical developments much stronger than any traditional concept in the pre-DSM-III decades [15].

Having a similar design and structure as its predecessor, DSM IV is released in 1994. Based on empirical data gathered in 14 years, several diagnostic criteria were refined and a few other disorders added, dropped, relabeled or reorganized. One subtle change was the dropping of the term "neurosis" which was thought to imply psychogenesis [3].

In terms of psychosomatic disorders, two main changes were included: Psychological factors affecting medical condition was replaced with Psychological factors affecting physical condition. More importantly, this section does not have the status of a category in itself; instead it was included as a subsection in another category: Other conditions that may be a focus of attention. Somatization disorder, Conversion disorder, Pain disorder, Hypochondriasis, Body dysmorphic disorder, Somatoform disorder and Somatoform disorder not otherwise specified are included in the same category.

The main criteria for Somatisation disorder listed in the DSM IV are as follows:

A. A history of many physical complaints beginning before age 30 years that occur over a period of several years and result in treatment being sought or significant impairment in social, occupational, or other important areas of functioning.

B. Each of the following criteria must have been met, with individual symptoms occurring at any time during the course of the disturbance:

(1) four pain symptoms

(2) two gastrointestinal symptoms

(3) one sexual symptom

(4) one pseudoneurological symptom

C. Either (1) or (2):

(1) each of the symptoms in Criterion B cannot be fully explained by a known general medical condition or the direct effects of a substance

(2) when there is a related general medical condition, the physical complaints or resulting social or occupational impairment are in excess of what would be expected from the history, physical examination, or laboratory findings

D. The symptoms are not intentionally feigned or produced.

A text revision of the DSM-IV, known as the DSM-IV-TR, was published in 2000. The diagnostic categories and the vast majority of the specific criteria for diagnosis were unchanged. This version of the DSM was used widely until recently when the newest edition of DSM was published.

There was for many years a need to improve the DSM-IV. Thus the DSM-V was finally created, after many years of patience. The evolution from DSM-I to DSM-V is displayed in Table I. 
American Psychiatric Association (1952). Diagnostic and Statistical Manual of Mental Disorders. Washington, DC: American Psychiatric Association.

American Psychiatric Association (1968). Diagnostic and Statistical Manual of Mental Disorders $2^{\text {nd }}$ ed. Washington, DC: American Psychiatric Association.

American Psychiatric Association (1980). Diagnostic and Statistical Manual of Mental Disorders $3^{\text {nd }}$ ed. Washington, DC: American Psychiatric Association.

American Psychiatric Association (1994). Diagnostic and Statistical Manual of Mental Disorders $4^{\text {nd }}$ ed. Washington, DC: American Psychiatric Association.

American Psychiatric Association (2013). Diagnostic and Statistical Manual of Mental Disorders $5^{\text {th }}$ ed. Arlington, VA: American Psychiatric Publishing.

\section{NEW DEVELOPMENTS - DSM V}

The most recent version of the DSM was published in 2013: DSM-V. A number of changes have been made from previous editions of DSM mainly aimed at reduction of the number of diagnoses and sub-diagnoses, removal of medically unexplained symptoms and focus on positive symptoms.

Somatization disorders and Psychological factors affecting a medical condition are now under the same category, called Somatic symptoms and related disorders; this change was made in order to eliminate overlap across the somatoform disorders and clarify their boundaries. Diagnoses of somatization disorder, hypochondriasis, somatoform disorder and somatoform disorder not otherwise specified were removed. According to this categorization, patients who experience chronic pain disorders can now be diagnosed with somatic symptoms, predominantly pain or psychological factors affecting a medical condition or with adjustment disorder.

Somatic symptoms disorder (SSD) (a combined category of somatization disorder and somatization disorder not otherwise specified) does not require a specific number of symptoms (as opposed to DSM IV). It is characterized by somatic symptoms that are either significantly distressing or result in significant disruption of functioning, as well as excessive and disproportionate thoughts, feelings and behaviors regarding those symptoms. Another key change in the DSM-5 is that while medically unexplained symptoms were a key feature for many of the disorders in DSM-IV, a Somatic symptoms disorder diagnosis does not require that the somatic symptoms are medically unexplained. In other words, whether or not the somatic symptoms are medically explained, the individual would still have to meet the rest of the criteria in order to receive a diagnosis of SSD; hence, patients who had organic comorbidities such as heart disease, osteoarthritis or cancer - who were previously excluded under
DSM-IV - can now be considered for a SSD diagnosis (www.dsm5.org).

DSM V has reformulated the diagnostic criteria in order to rely less on strict patterns of somatic symptoms and more on the degree to which a patient's thoughts, feelings and behaviours about their symptoms are disproportionate or excessive. The symptoms are generally severe enough to affect work and relationships and lead the person to consult a doctor and take medication.

The main criteria listed in the DSM V are as follows (16):

A. Somatic symptoms

B. Excessive thoughts, feelings and behaviors related to these somatic symptoms or associated health concerns:

(1) High level of health-related anxiety

(2) Disproportionate and persistent concerns about the medical seriousness of one's symptoms

(3) Excessive time and energy devoted to these symptoms or health concerns

C. Chronicity: the state of being somatic lasts for more than 6 months.

Patients with SSD have one of the following as a dominate symptoms: somatic complaints, health anxiety, and pain

As the diagnostic criteria show, DSM V now focuses, not only on somatic symptoms but also on psychological responses, including the patient's emotions, thinking and behavior of their symptoms. Until a new version of the DSM is published, these are the main diagnostic criteria to be used in assessing psychosomatic symptoms.

\section{CONCLUSIONS}

The need for a classification of mental disorders has been clear throughout the history of medicine, but until recently there was little 
agreement on which disorders should be included and the optimal method for their organization.

Over the past decades, modern diagnostic systems have struggled to find even a suitable name for somatic disorders. From various terms to total abolishment of the category or lowering of threshold for inclusion of less severe, but more common versions with necessary regroupings of subcategories, there have been a wide range of recommendations.

Internists should become familiar with the entities characterized and classified in the most recent DSM edition, as it includes some categorical changes.

Aşa numitele „Simptome psihosomatice” reprezintă o provocare pentru internişti. Aceste simptome au fost frecvent descrise ca nespecifice, ne-organice, funcționale, disfuncționale sau idiopatice. Aceste „puzzles” diagnostice sunt desigur greu de tratat. Simptomele psihosomatice au fost categorizate ca isterie, psihogene, psihosomatice, tulburări de conversie, somatizare şi tulburări somatoforme. Sistemele moderne de clasificare precum Diagnostic and Statistical Manual (DSM) şi Clasificarea Internațională a Maladiilor (CMI) au stimulat cercetarea și au permis o mai pregnantă identificare clinică a acestor tulburări. Prezentul articol arată succint evoluția simptomelor psihosomatice din perspectiva DSM, cu accent pe avantajele şi provocările acestui sistem de clasificare. Sunt discutate perspectivele deschise odată cu apariția ediției a cincea a DSM, DSM-V.

\section{REFERENCES}

1. SHEPHERD M, COOPER R, BROWN AC, KALTON GW (1966). Psychiatric illness in general practice. Oxford University Press, London.

2. MAYOU R. Medically unexplained physical symptoms. Br Med J, 1991, 303, 534-35.

3. OKEN D. Evolution of psychosomatic diagnosis in DSM. Psychosom Med, 2007, 69, 830-1.

4. VEIGH I. Hysteria: the history of a disease. University of Chicago Press, Chicago, 1965.

5 BOSS JMN. The seventeenth century transformation of the hysteric affection, and Sydemham's Baconiam medicine. Psychol Med, 1979, 9, 221-34.

6 KALLIVAYALIL RA \& PUNNOOSE VP, Understanding and managing somatoform disorders: Making sense of non-sense. Indian J Psychiatry, 2010, 52, 240-245.

7. JANA AK \& PRAHARAJ SK \& MAZUMDAR J. Current debates over nosology of somatoform disorders. Ind Psychiatry, 2012, 21, 4-10.

8. LIPOWSKI ZJ. Somatization: The concept and its clinical application. Am J Psychiat, 1988, 145, 1358-68.

9. HINSIE LE \& CAMPBELL RJ. Psychiatric dictionary, Oxford University Press, New York, 1960.

10. FAVA GA, SONINO N. The clinical domains of psychosomatics medicine. J Clin Psychiatry, 2005, 66, 849-58.

11. GITLIN DF, LEVENSON JL, LYKETSOS CG. Psychosomatic medicine: a new psychiatric subspecialty. Acad Psychiatry, 2004, 28, 4-11.

12. BĂBAN A, DUMITRAŞCU DL. Somatisation: a modern concept for a classic clinical syndrome, Journal of of Medical Life, 1991, 8.

13. DIMSDALE JE, XIN Y, KLEINMAN A, PATEL V, NARROW WE, SIROVATKA PJ, REGIER DA. Somatic Presentations of mental disorders: refining the research agenda for DSM-5. Arlington VA: American Psychiatric Association, 2009.

14. FINK P. Somatization disorder and related disorders. In: GELDER MG, LOPEZ-IBOR JJ, ANDREASEN NC, editors. New Oxford Textbook of Psychiatry. New York: Oxford University Press, 2000.

15. HILLER W, RIEF W. Why DSM-III was right to introduce the concept of somatoform disorders. Psychosomatics, 2005, 46, $105-8$.

16. GHANIZADEH A, FIROOZABADI A. A review of somatoform disorders in DSM-IV and somatic symptom disorders in proposed DSM-V. Psychiatr Danub, 2012, 24, 353-8.

Received February 10, 2015 